\title{
Editorial: Heme Oxygenases: Novel Regulators of Reproductive Processes
}

\author{
Ronald J. Wong ${ }^{1}$ and Ana C. Zenclussen ${ }^{2 *}$ \\ ${ }^{1}$ Division of Neonatal and Developmental Medicine, Department of Pediatrics, Stanford University School of Medicine, \\ Stanford, CA, USA, ${ }^{2}$ Experimental Obstetrics and Gynecology, Medical Faculty, Otto-von-Guericke University, Magdeburg, \\ Magdeburg, Germany
}

Keywords: Hmox1, HO-1, placenta, uterus, pregnancy, immune system, pre-eclampsia

\section{OPEN ACCESS}

Edited by:

Irina Burd,

Johns Hopkins University School of

Medicine, USA

Reviewed by:

Emily J. Su,

University of Colorado School of Medicine, USA

Arthur Jason Vaught,

Johns Hopkins Hospital, USA

*Correspondence:

Ana C. Zenclussen

ana.zenclussen@med.ovgu.de

Specialty section:

This article was submitted to Obstetric and Pediatric Pharmacology, a section of the journal

Frontiers in Pharmacology

Received: 09 September 2015 Accepted: 10 November 2015 Published: 27 November 2015

Citation:

Wong RJ and Zenclussen AC (2015) Editorial: Heme Oxygenases: Novel Regulators of Reproductive Processes. Front. Pharmacol. 6:282. doi: 10.3389/fphar.2015.00282
Heme oxygenase $(\mathrm{HO})$ is a ubiquitous enzyme with various properties, but its main function is catalyzing the rate-limiting step in heme degradation to produce equimolar quantities of biliverdin, iron, and carbon monoxide (CO) (Tenhunen et al., 1968). Of its three isozymes, HO-2 and HO-3 are constitutively-expressed and HO-1 is inducible and acts as stress-response protein. It is not only cytoprotective (Vile et al., 1994; Soares et al., 1998; Gozzelino et al., 2010); but also, exerts anti-inflammatory effects (Otterbein et al., 2000, 2003; Soares and Bach, 2009). Together with its modulatory effects on cell proliferation (Duckers et al., 2001; Lee and Chau, 2002), HO-1 can prevent tissue injury. Also, HO-1 is known to regulate innate and adaptive immunity, and therefore may prevent immune-mediated inflammatory diseases (Wagener et al., 2003; Soares and Bach, 2009; Soares et al., 2009). These effects can be inhibited pharmacologically and restored by CO (Brouard et al., 2000; Otterbein et al., 2000; Lee and Chau, 2002; Ryter et al., 2002; Kim et al., 2006).

Pioneering work from the late Fritz Bach revealed the importance of HO-1 in organ transplantation. Using wild-type (WT, Hmoxi ${ }^{+/+}$) and $H m o x 1^{-/-}$mice, Soares et al. (1998) demonstrated that the rapid expression of HO-1 by xenograft endothelial cells, smooth muscle cells, and cardiac myocytes protects xenografts from rejection. The role of HO-1 in xenograft and allograft acceptance is due to its cytoprotective properties that support cell survival and function within the transplanted organ. Moreover, HO-1 can reduce the graft immunogenicity by directly modulating recipient immune response such that regulatory responses are generated. The activation of HO-1 expression in the graft and in immune cells of the recipient can prevent rejection and promote immunotolerance, and probably due to the detoxification of free heme by HO-1 (Soares and Bach, 2007).

Using a mouse model where tolerance is induced by donor-specific transfusion and anti-CD40L, Yamashita et al. (2006) observed that HO-1 is necessary for long-term graft tolerance as grafts do not survive in $H_{m o x 1^{-/-}}$compared to WT control recipients. Modulation of HO-1 was necessary to promote graft tolerance. Donor-specific transfusion alone failed to prolong survival of transplanted hearts, but long-term survival and tolerance were achieved after HO-1 induction. HO-1 induction plus donor-specific transfusion was associated with increases in regulatory T-cells (Tregs) (Yamashita et al., 2006). The immunomodulatory effect on cells from graft recipients is based on the fact that HO-1 directly modulates the phenotype of dendritic cells (DCs) (Moreau et al., 2009). HO-1 is constitutively expressed in immature DCs; however, its expression decreases during DC maturation. HO-1 upregulation can maintain DCs in an immature state, which suppresses the immune response, and then leads to antigen-specific Treg generation (George et al., 2008; Schumacher et al., 2012). Because Tregs from Hmox1 $1^{-/}$mice are functional, it can be concluded that the suppressive function of Tregs depends upon HO-1-induced modulation of DCs rather than HO-1 expression by Tregs (Zelenay et al., 2007). 
In the article by Schumacher and Zenclussen (2015), the participation of HO-1 in immunomodulation during pregnancy and organ transplantation is discussed. They report how HO1 promotes alloantigen tolerance by blocking DC maturation reduces T-cell responses and increases Treg numbers. Further mechanisms involve the cytokine milieu, tissue protection, and apoptosis. Hence, HO-1 can mediate acceptance of a transplanted allogeneic graft through organ cytoprotection and immunotolerance. A similar scenario may be true for a growing fetus, which is semi-allogeneic to the mother, where HO-1 confers both semi-allograft cytoprotection and immunotolerance in the maternal immune system.

Because of its role in the modulation of innate and adaptive immune responses, $\mathrm{HO}-1$ is linked to carcinogenesis by influencing tumor induction, growth, and metastasis (Jozkowicz et al., 2007). HO-1 is highly expressed in several tumors, and accordingly, inhibition of $\mathrm{HO}$ may have potential as a therapeutic approach. Because tumors are highly vascularized and prone to massive hemorrhaging, large quantities of free heme can be released, and induce $\mathrm{HO}-1$ that in turn negatively influences the host and protects the tumor from oxidative injury. HO-1 is also involved in tumor angiogenesis and stimulating tumorassociated macrophages (Was et al., 2010), and thus, may regulate tumor survival and progression.

Zhao et al. (2015) discuss how HO-1 regulates similar processes in transplantation and pregnancy, particularly in invasion and neovascularization. Pregnancy is a physiological state characterized by interactions of various processes occurring at different stages. For these changes to occur, tissue and vascular remodeling as well as both pro- and anti-inflammatory processes in the uterus are required. However, once the placenta has formed and the fetus grows, the fetoplacental unit behaves more like a graft that is tolerated by its host. When pregnancy is

\section{REFERENCES}

Brouard, S., Otterbein, L. E., Anrather, J., Tobiasch, E., Bach, F. H., Choi, A. M., et al. (2000). Carbon monoxide generated by heme oxygenase 1 suppresses endothelial cell apoptosis. J. Exp. Med. 192, 1015-1026. doi: 10.1084/jem.192.7.1015

Duckers, H. J., Boehm, M., True, A. L., Yet, S. F., San, H., Park, J. L., et al. (2001). Heme oxygenase-1 protects against vascular constriction and proliferation. Nat. Med. 7, 693-698. doi: 10.1038/89068

George, E. M., Hosick, P. A., Stec, D. E., and Granger, J. P. (2013). Heme oxygenase inhibition increases blood pressure in pregnant rats. Am. J. Hypertens. 26, 924-930. doi: 10.1093/ajh/hpt045

George, E. M., Stout, J. M., Stec, D. E., and Granger, J. P. (2015). Heme oxygenase induction attenuates TNF-alpha-induced hypertension in pregnant rodents. Front. Pharmacol. 6:165. doi: 10.3389/fphar.2015.00165

George, J. F., Braun, A., Brusko, T. M., Joseph, R., Bolisetty, S., Wasserfall, C. H., et al. (2008). Suppression by CD4+CD25+ regulatory T cells is dependent on expression of heme oxygenase-1 in antigen-presenting cells. Am. J. Pathol. 173, 154-160. doi: 10.2353/ajpath.2008.070963

Gozzelino, R., Jeney, V., and Soares, M. P. (2010). Mechanisms of cell protection by heme oxygenase-1. Annu. Rev. Pharmacol. Toxicol. 50, 323-354. doi: 10.1146/annurev.pharmtox.010909.105600

Jozkowicz, A., Was, H., and Dulak, J. (2007). Heme oxygenase-1 in tumors: is it a false friend? Antioxid. Redox Signal. 9, 2099-2117. doi: 10.1089/ars. 2007.1659 near completion, the semi-allograft is naturally "rejected" by the mother resulting in birth.

Zenclussen et al. (2015) review how HO-1 impacts reproductive processes, highlighting its importance in placental function and fetal development. The deletion of Hmox1 in mice leads to inadequate spiral artery remodeling and suboptimal placentation followed by intrauterine growth restriction and fetal death (Zhao et al., 2009; Zenclussen et al., 2011). A partial Hmox 1 deletion is compatible with pregnancy, however heterozygote females develop gestational hypertension (Linzke et al., 2014). The protective effects of HO-1 on placentation and fetal growth can be mimicked by exogenous administration of $\mathrm{CO}$. CO promotes the in situ proliferation of uterine natural killer (uNK) cells, restores placentation, and fetal growth, while normalizing blood pressure (Linzke et al., 2014). Similarly, HO-1 inhibition provokes hypertension in pregnant rats (George et al., 2013).

The relevance of HO-1 in the regulation of immune responses during pregnancy is further highlighted in the article by George et al. (2015). They investigated whether HO-1 induction could attenuate TNF- $\alpha$-induced hypertension in pregnancy. HO-1 induction significantly decreased blood pressure in TNF- $\alpha-$ infused animals, which was accompanied by a normalization of vascular parameters, supporting the notion that $\mathrm{HO}-1$ is essential in counteracting the negative effects of excessive inflammation.

In summary, the $\mathrm{HO}-1 / \mathrm{CO}$ axis may play a pivotal role in sustaining pregnancy, and thus understanding its biology during pregnancy may reveal promising therapeutic approaches for pregnancy complications.

\section{AUTHOR CONTRIBUTIONS}

Both the authors contributed in writing the editorial.
Kim, H. J., So, H. S., Lee, J. H., Lee, J. H., Park, C., Park, S. Y., et al. (2006). Heme oxygenase-1 attenuates the cisplatin-induced apoptosis of auditory cells via down-regulation of reactive oxygen species generation. Free Radic. Biol. Med. 40, 1810-1819. doi: 10.1016/j.freeradbiomed.2006.01.018

Lee, T. S., and Chau, L. Y. (2002). Heme oxygenase-1 mediates the antiinflammatory effect of interleukin-10 in mice. Nat. Med. 8, 240-246. doi: $10.1038 / \mathrm{nm} 0302-240$

Linzke, N., Schumacher, A., Woidacki, K., Croy, B. A., and Zenclussen, A. C. (2014). Carbon monoxide promotes proliferation of uterine natural killer cells and remodeling of spiral arteries in pregnant hypertensive heme oxygenase-1 mutant mice. Hypertension 63, 580-588. doi: 10.1161/HYPERTENSIONAHA.113.02403

Moreau, A., Hill, M., Thébault, P., Deschamps, J. Y., Chiffoleau, E., Chauveau, C., et al. (2009). Tolerogenic dendritic cells actively inhibit $\mathrm{T}$ cells through heme oxygenase-1 in rodents and in nonhuman primates. FASEB J. 23, 3070-3077. doi: 10.1096/fj.08-128173

Otterbein, L. E., Bach, F. H., Alam, J., Soares, M., Tao Lu, H., Wysk, M., et al. (2000). Carbon monoxide has anti-inflammatory effects involving the mitogen-activated protein kinase pathway. Nat. Med. 6, 422-428. doi: 10.1038/ 74680

Otterbein, L. E., Soares, M. P., Yamashita, K., and Bach, F. H. (2003). Heme oxygenase-1: unleashing the protective properties of heme. Trends Immunol. 24, 449-455. doi: 10.1016/S1471-4906(03)00181-9

Ryter, S. W., Otterbein, L. E., Morse, D., and Choi, A. M. (2002). Heme oxygenase/carbon monoxide signaling pathways: regulation and 
functional significance. Mol. Cell. Biochem. 234-235, 249-263. doi: 10.1023/A:1015957026924

Schumacher, A., Wafula, P. O., Teles, A., El-Mousleh, T., Linzke, N., Zenclussen, M. L., et al. (2012). Blockage of heme oxygenase-1 abrogates the protective effect of regulatory $\mathrm{T}$ cells on murine pregnancy and promotes the maturation of dendritic cells. PLoS ONE 7:e42301. doi: 10.1371/journal.pone.0042301

Schumacher, A., and Zenclussen, A. C. (2015). Effects of heme oxygenase-1 on innate and adaptive immune responses promoting pregnancy success and allograft tolerance. Front. Pharmacol. 5:288. doi: 10.3389/fphar.2014.00288

Soares, M. P., and Bach, F. H. (2007). Heme oxygenase-1 in organ transplantation. Front. Biosci. 12, 4932-4945. doi: 10.2741/2439

Soares, M. P., and Bach, F. H. (2009). Heme oxygenase-1: from biology to therapeutic potential. Trends Mol. Med. 15, 50-58. doi: 10.1016/j.molmed.2008.12.004

Soares, M. P., Lin, Y., Anrather, J., Csizmadia, E., Takigami, K., and Sato, K., et al. (1998). Expression of heme oxygenase-1 can determine cardiac xenograft survival. Nat. Med. 4, 1073-1077. doi: 10.1038/2063

Soares, M. P., Marguti, I., Cunha, A., and Larsen, R. (2009). Immunoregulatory effects of HO-1: how does it work? Curr. Opin. Pharmacol. 9, 482-489. doi: 10.1016/j.coph.2009.05.008

Tenhunen, R., Marver, H. S., and Schmid, R. (1968). The enzymatic conversion of heme to bilirubin by microsomal heme oxygenase. Proc. Natl. Acad. Sci. U.S.A. 61, 748-755. doi: 10.1073/pnas.61.2.748

Vile, G. F., Basu-Modak, S., Waltner, C., and Tyrrell, R. M. (1994). Heme oxygenase 1 mediates an adaptive response to oxidative stress in human skin fibroblasts. Proc. Natl. Acad. Sci. U.S.A. 91, 2607-2610. doi: 10.1073/pnas.91.7.2607

Wagener, F. A., van Beurden, H. E., von den Hoff, J. W., Adema, G. J., and Figdor, C. G. (2003). The heme-heme oxygenase system: a molecular switch in wound healing. Blood 102, 521-528. doi: 10.1182/blood-2002-07-2248

Was, H., Dulak, J., and Jozkowicz, A. (2010). Heme oxygenase-1 in tumor biology and therapy. Curr. Drug Targets 11, 1551-1570. doi: $10.2174 / 1389450111009011551$
Yamashita, K., Ollinger, R., McDaid, J., Sakahama, H., Wang, H., Tyagi, S., et al. (2006). Heme oxygenase-1 is essential for and promotes tolerance to transplanted organs. FASEB J. 20, 776-778. doi: 10.1096/fj.054791fje

Zelenay, S., Chora, A., Soares, M. P., and Demengeot, J. (2007). Heme oxygenase1 is not required for mouse regulatory $\mathrm{T}$ cell development and function. Int Immunol. 19, 11-18. doi: 10.1093/intimm/dxl116

Zenclussen, M. L., Casalis, P. A., El-Mousleh, T., Rebelo, S., Langwisch, S., Linzke, N., et al. (2011). Haem oxygenase-1 dictates intrauterine fetal survival in mice via carbon monoxide. J. Pathol. 225, 293-304. doi: 10.1002/path.2946

Zenclussen, M. L., Linzke, N., Schumacher, A., Fest, S., Meyer, N., Casalis, P. A., et al. (2015). Heme oxygenase-1 is critically involved in placentation, spiral artery remodeling, and blood pressure regulation during murine pregnancy. Front. Pharmacol. 5:291. doi: 10.3389/fphar.2014.00291

Zhao, H., Ozen, M., Wong, R. J., and Stevenson, D. K. (2015). Heme oxygenase- 1 in pregnancy and cancer: similarities in cellular invasion, cytoprotection, angiogenesis, and immunomodulation. Front. Pharmacol. 5:295. doi: 10.3389/fphar.2014.00295

Zhao, H., Wong, R. J., Kalish, F. S., Nayak, N. R., and Stevenson, D. K. (2009). Effect of heme oxygenase-1 deficiency on placental development. Placenta 30 , 861-868. doi: 10.1016/j.placenta.2009.07.012

Conflict of Interest Statement: The authors declare that the research was conducted in the absence of any commercial or financial relationships that could be construed as a potential conflict of interest.

Copyright (๑ 2015 Wong and Zenclussen. This is an open-access article distributed under the terms of the Creative Commons Attribution License (CC BY). The use, distribution or reproduction in other forums is permitted, provided the original author(s) or licensor are credited and that the original publication in this journal is cited, in accordance with accepted academic practice. No use, distribution or reproduction is permitted which does not comply with these terms. 